Swarthmore College

Works

2-1-2011

\title{
Effects Of Attenuation And Thrombus Age On The Success Of Ultrasound And Microbubble-Mediated Thrombus Dissolution
}

F. Xie

E. Carr Everbach

Swarthmore College, ceverba1@swarthmore.edu

S. J. Gao

L. K. Drvol

W. T. Shi

See next page for additional authors

Follow this and additional works at: https://works.swarthmore.edu/fac-engineering

Part of the Engineering Commons

Let us know how access to these works benefits you

\section{Recommended Citation}

F. Xie, E. Carr Everbach, S. J. Gao, L. K. Drvol, W. T. Shi, F. Vignon, J. E. Powers, J. Lof, and T. R. Porter. (2011). "Effects Of Attenuation And Thrombus Age On The Success Of Ultrasound And MicrobubbleMediated Thrombus Dissolution". Ultrasound In Medicine And Biology. Volume 37, Issue 2. 280-288. DOI: 10.1016/j.ultrasmedbio.2010.10.022

https://works.swarthmore.edu/fac-engineering/7

This work is brought to you for free by Swarthmore College Libraries' Works. It has been accepted for inclusion in Engineering Faculty Works by an authorized administrator of Works. For more information, please contact myworks@swarthmore.edu. 


\section{Authors}

F. Xie, E. Carr Everbach, S. J. Gao, L. K. Drvol, W. T. Shi, F. Vignon, J. E. Powers, J. Lof, and T. R. Porter 


\title{
Effects of Attenuation and Thrombus Age on the Success of Ultrasound and Microbubble Mediated Thrombus Dissolution
}

\author{
Feng Xie, MD ${ }^{1}$, Carr Everbach, PhD ${ }^{2}$, Shunji Gao, MD ${ }^{1}$, Lucas K Drvol, BS ${ }^{1}$, William T Shi, \\ $\mathrm{PhD}^{3}$, Francois Vignon, $\mathrm{PhD}^{3}$, Jeff E Powers, PhD $^{4}$, John Lof, $\mathbf{M S}^{1}$, and Thomas R Porter, \\ $\mathrm{MD}^{1}$ \\ ${ }^{1}$ Department of Internal Medicine, Section of Cardiology, University of Nebraska Medical Center, \\ Omaha, NE \\ ${ }^{2}$ Swarthmore College, Swarthmore, PA \\ ${ }^{3}$ Philips Research North America, 345 Scarborough Road, Briarcliff Manor, NY 10510 \\ ${ }^{4}$ Philips Healthcare, 22100 Bothell Everett Highway, Bothell, WA 98021
}

\begin{abstract}
The purpose of this study was to examine the effects of applied mechanical index, incident angle, attenuation, and thrombus age on the ability of $2 \mathrm{D}$ versus $3 \mathrm{D}$ diagnostic ultrasound and microbubbles to dissolve thrombi. A total of 180 occlusive porcine arterial thrombi of varying age ( 3 or 6 hours) were examined in a flow system. A tissue-mimicking phantom of varying thickness $(5-10 \mathrm{~cm})$ was placed over the thrombosed vessel and the 2D or 3D diagnostic transducer aligned with the thrombosed vessel using a positioning system. Diluted lipid encapsulated microbubbles were infused during ultrasound application. Percent thrombus dissolution (\%TD) was calculated by comparison of clot mass before and after treatment. Both 2D and 3D guided ultrasound increased \% TD compared to microbubbles alone, but \% TD achieved with six hour old thrombi was significantly less than three hour old thrombi. Thrombus dissolution was achieved at $10 \mathrm{~cm}$ tissue mimicking depths, even without inertial cavitation. In conclusion, diagnostic $2 \mathrm{D}$ or $3 \mathrm{D}$ ultrasound can dissolve thrombi with intravenous non-targeted MB even at tissue attenuation distances of up to 10 centimeters. This treatment modality is less effective, however, for older aged thrombi.
\end{abstract}

\section{Keywords}

Thrombus; Microbubbles; Three-dimensional ultrasound

\section{Introduction}

Ultrasound has been studied as an adjunctive treatment to thrombolytic drugs, as well as an independent treatment method without thrombolytic drugs for vascular thrombosis (Dhond

(C) 2010 World Federation for Ultrasound in Medicine and Biology. Published by Elsevier Inc. All rights reserved.

Corresponding Author: Feng Xie, MD, University of Nebraska Medical Center, 982265 Nebraska Medical Center, Omaha NE 68198-2265, Telephone: (402) 559-7977; Fax: (402) 559-8355, fxie@unmc.edu.

Publisher's Disclaimer: This is a PDF file of an unedited manuscript that has been accepted for publication. As a service to our customers we are providing this early version of the manuscript. The manuscript will undergo copyediting, typesetting, and review of the resulting proof before it is published in its final citable form. Please note that during the production process errors may be discovered which could affect the content, and all legal disclaimers that apply to the journal pertain. 
et al. 2000; Molina et al. 2006; Porter et al. 1996; Siegel et al. 2001; Suchkova et al. 2000; Tachibana and Tachibana 1995; Tiukinhoy-Laing et al. 2007; Xie et al. 2005). In animal studies, low frequency transthoracic ultrasound has enhanced the effectiveness of thrombolytic agents, permitting a lower dose of lytic agent to be used, and shortening the time to reperfusion in experimental animals (Kawata et al. 2007). However, when such trials were attempted in humans using an externally applied transthoracic ultrasound system, ultrasound did not increase the coronary recanalization rates of fibrinolytic agents. Ultrasound-induced thrombolysis is augmented in the presence of microbubbles, even when using diagnostic ultrasound transducers (Molina et al. 2006; Xie et al. 2007). Despite success in peripheral vascular thromboses, the success rate of ultrasound and intravenous microbubbles in recanalizing acute coronary thromboses has been lower (Porter et al. 2001). In addition to beam attenuation, the reasons for the reduced success rate may be the diagnostic transducer's small beam width, limited duty cycle, and angle with which the coronary artery is positioned in relation to the transducer beam. The purpose of this study was to examine the effects of these variables on the ability of diagnostic ultrasound and microbubbles to dissolve thrombi without the aid of a fibrinolytic agent.

\section{Material and Methods}

\section{Experimental apparatus}

The overall experimental arrangement consisted of large acrylic tank $(100 \mathrm{~cm} \times 50 \mathrm{~cm} \times 40$ $\mathrm{cm}$ ) filled with distilled deionized water (Fig. 1). The set-up included a flow system, a five and 10 centimeter thick tissue-mimicking phantom (TMP) with an adaptor module, cavitation detector/hydrophone positioning system, transducer positioning system, data display, collecting and analysis system, along with a two and three-dimensional ultrasound system.

Flow within the tubing ( $2.6 \mathrm{~mm}$ internal diameter) was controlled by a Master-flex flow pump (Cole Parmer Instrument Co., Vernon Hills, IL). Phosphate-buffered saline (PBS) in a large beaker was maintained at $37^{\circ} \mathrm{C}$ using an Isotemp digital stirring hotplate (Fisher Scientific, Dubuque, IA), which was pumped through the tube system at a constant flow rate of $20 \mathrm{~mL} / \mathrm{min}$. This flow rate simulates the flow rate of human or pig mid left anterior descending coronary artery in an underperfused state (Hildick-Smith et al. 2000, Ootaki et al. 2005). A bypass-vessel was aligned in parallel to the thrombosed vessel to prevent the high pressure produced by thrombotic occlusion (Figure 2). The bypass-vessel and thrombosed vessel (T-connector) were kept at the same level to ensure equal pressure in the flow system. The tube system was then placed under the tissue-mimicking phantom.

Two tissue-mimicking phantoms (TMP) were designed by Computerized Imaging References Systems, Inc (Norfolk, VA, USA). These two TMPs had different thicknesses of five and $10 \mathrm{~cm}$, respectively. According to the manufacturer, the phantoms attenuated ultrasound at $0.49 \mathrm{~dB} / \mathrm{cm} / \mathrm{MHz}$. Two phantom adaptor modules made from acrylic were designed to test the effects of different angles of insonation with respect to the vessel (45 degrees and 90 degrees as demonstrated in Figure 3).

The base of the adaptor module had an eight by eight centimeter cut-out that was used for exchange of thrombi within the T-shaped connectors. An epoxy holder was extended from the edge of the hole to hold the T-connector in place. Plastic clips on the module were used to lock the extended tubes. To exchange the T- connector for each experimental run, the extended tubes were released and the exchange procedure performed above water to prevent microbubble leak into the water tank. During the angulation study, a separate acrylic stand was used that permitted the phantom to sit at a 45 degree angle with respect to the thrombus. 
This stand was fixed to the side of the tank in the same fashion as the 90 degree insonation angle study.

The ultrasound transducer was held in position by a clamp holder attached to a ringstand. It was mechanically adjusted left or right to align the beam over the thrombus. For the angulation studies, the holder was screwed on to the stand to create a 45 degree angle between the beam with respect to the thrombus (Figure 3).

\section{Arterial vascular access and clot preparation}

Arterial whole blood samples were obtained from a healthy pig. The blood withdrawal procedures were compliant with the Guidelines of the Institutional Animal Care and Use Committee (IACUC) and the Standards in the Guide for the Care and Use of Laboratory Animals. An arterial vascular access catheter was placed in the right carotid artery and tunneled subcutaneously to the dorsal region of the chest wall. On the day of the experiment, a 2.0-mL sample was collected and $3 \mathrm{IU} / \mathrm{mL}$ thrombin (Sigma Aldrich, Milwaukee, WI) added into the blood. This dose of thrombin was chosen as it was the minimum dose required to produce adherent thrombi at three hours. A 40- $\mu \mathrm{L}$ sample of this thrombin-whole blood mixture was injected into the T- connectors. These samples were then allowed to stand at room temperature $\left(22^{\circ} \mathrm{C}\right)$ for three and six hours prior to being placed in the set-up described above.

\section{Microbubbles}

Definity, a lipid-encapsulated commercially available microbubble (Lantheus Medical Imaging, N. Billerica, MA) was used for all experiments. The mean diameter size of these microbubbles is $1.1-3.3 \mu \mathrm{m}$, and concentration $1.2 \times 10^{10}$ microbubbles $/ \mathrm{mL}$. During the experiment, $0.5 \mathrm{~mL}$ Definity was added in $100 \mathrm{~mL}$ normal saline and then infused at $1 \mathrm{~mL} /$ min via a stopcock into the flow system. This resulted in approximately $6 \times 10^{7}$ microbubbles per minute flowing through the connector/bypass system displayed in Figure 2.

\section{Two and Three Dimensional Ultrasound Systems}

An iE33 diagnostic scanner (Philips Healthcare, Andover, MA), equipped with a threedimensional (3D) matrix array X3-1 and a two-dimensional (2D) sector array S5-1, were used in this study. A center frequency of 1.6 MHz was used for both the S5-1 and X3-1 transducer. The 3D volume covered for these experiments was a $30 \times 60$ degree field. In order to assess what peak negative pressure field was reaching the thrombus during the high mechanical index applications, a $0.5 \mathrm{~mm}$ needle hydrophone (Precision Acoustics, Dorchester, UK) was placed at distances of five and 10 centimeters from each transducer face (with and without the presence of the TMP) and moved to different locations with a positioning system, covering a region of $100 \times 100 \mathrm{~mm}$ using axial and lateral steps of 10 $\mathrm{mm}$. At each point, the signal from the hydrophone was acquired during three complete sector sweeps of the phased array. The focus point of the transducer was placed at a distance of between five and 10 centimeters from the transducer face. The acoustic power output of the scanner was adjusted to $1.1 \mathrm{MI}$ for both the X3-1 transducer and s5-1 transducer during these measurements.

The hydrophone output was transmitted into a $50 \mathrm{ohm}$ input of a WaveRunner-64MXi digital oscilloscope (LeCroy Corporation, Chestnut Ridge, NY) set to display $50 \mathrm{~ms}$ of data and to calculate the RMS and peak negative voltages using its internal scope software. A computer running a Matlab program acquired this data from the scope ten times in succession for each hydrophone location and recorded the average of the ten measurements of both RMS amplitude and peak negative voltage. After each average was calculated and 
transferred to a file, the three-axis positioning system was advanced to a new location and the procedure repeated.

\section{Cavitation measurements}

A computer-controlled 3-axis positioner (Velmex ${ }^{\circledR}$ Unislide $^{\mathrm{TM}}$ ) was mounted on the tank. This positioner could locate the co-focus of a pair of $20 \mathrm{MHz}$ single-crystal ultrasound transducers with $10 \mu \mathrm{m}$ spatial resolution. The transducers, whose 1-mm-diameter beams cross at right angles, served as detectors of inertial cavitation occurring at their co-focus by passively recording the $20 \mathrm{MHz}$ components of bubble collapse acoustic emissions. Each transducer's output signal was amplified, filtered, and displayed on a different trace of the digital oscilloscope. A data acquisition program, written in Matlab®, collected the data from a confocal volume within the lumen of the tubing and recorded acoustic signals only from the cavitation signals that occurred in both channels simultaneously. Triggering of the oscilloscope by a custom-designed output signal from the Philips iE33 scanner assured that the only cavitation signals resulting from scan lines within the tubing were being recorded. Measurements within the lumen were made in the presence of and in the absence of microbubbles, and using both the five and 10 centimeter tissue mimicking phantom thicknesses.

\section{Experimental Protocols}

A $0.5 \%$ infusion of microbubbles (Definity; Lantheus Inc.) at $1 \mathrm{ml} / \mathrm{min}$ was continuously administered, and mixed with an infusion of PBS at $37^{\circ} \mathrm{C}$. Treatments were randomized based on a) diagnostic ultrasound transducer (two- or three-dimensional), b) thrombus age; c) TMP thickness, and d) angle of transducer with respect to the thrombus (transducer angulation). Each transducer was set to continuously monitor for the presence of microbubbles within the vessel using low mechanical index (MI) imaging (Power Modulation at $<0.2 \mathrm{MI}$ ). The high MI impulses (1.1 MI for both transducers) were delivered when microbubbles were visualized near or within the thrombus, and were applied for a 10 second period followed by a 10 second off time to allow for microbubble replenishment. The thrombus weight before and after treatment was measured. Total treatment time was 10 minutes.

Before testing, each thrombus sample was placed and weighed on a balance with $0.001 \mathrm{~g}$ resolution (Adam Equipment Inc, Milton Keynes, England). After treatment, the sample was dried by 30-minute air blow and weighed on same balance. Percent thrombus dissolution (\%TD) was calculated by comparison of clot mass before and after treatment.

To further identify potential mechanisms by which three hour thrombi may be more susceptible to dissolution with ultrasound and microbubbles, loops of occlusive arterial thrombi were formed in $4 \mathrm{~mm}$ diameter silastic tubing and imaged within the same flow system at three and six hours following thrombus formation. Low MI imaging (Contrast Pulse Sequencing; Siemens Acuson Sequoia) was performed through a $2 \mathrm{~mm}$ thick tissue mimicking phantom to examine for the presence or absence of microbubbles within the thrombus during a $0.5 \%$ Definity infusion that was applied at a standard pressure of 100 $\mathrm{mm} \mathrm{Hg}$.

\section{Statistical Comparisons}

All data are expressed as mean \pm SD values or number and percentages. Paired t testing was used for changes in thrombus mass before and after each randomized treatment. Analysis of variance was used for comparison of different treatment combinations. A Fisher Exact test was used to compare differences in the proportion of thrombus that was present during Definity infusion. A probability value $<0.05$ was considered statistically significant. 


\section{Results}

\section{Peak Negative Pressure Fields Created by the three and two-dimensional ultrasound transducer}

Figure 4 displays the contours of peak negative pressure produced by the 2D and 3D diagnostic ultrasound transducers at the high MI (1.1) setting. Although the 3D transducer had a broader coverage, the two dimensional transducer had a higher peak negative pressure at the center position of the beam. Table 1 summarizes the converted measurements of peak negative pressure with the $2 \mathrm{D}$ and $3 \mathrm{D}$ transducer at the different distances from the transducer face. At the 10 centimeter TMP distance, the peak negative pressure for the 3D transducer was reduced to 270 kilopascals.

\section{Effects of thrombus age and attenuation on thrombolysis}

A total of 100 porcine arterial thrombi of varying age ( 3 or 6 hours) were tested with $2 \mathrm{D}$ or 3D ultrasound to test the effect of thrombus age and TMP thickness on ultrasound and microbubble-induced thrombus dissolution. Table 2 summarizes the results. Note that the intermittent 1.1 MI impulses from both the 2D and 3D increased \% TD compared to control (MB infused alone without ultrasound), irrespective of thrombus age or TMP thickness $(\mathrm{p}<0.01)$. However, \% TD achieved with six hour old thrombi was significantly less than that achieved with a three hour old thrombus (Figure 5).

Figure 6 is an example of low MI imaging through an occlusive arterial thrombus at three hours versus six hours age. Microbubbles were visualized transiting through small channels in seven of the nine thrombi at three hours versus only two of eight occlusive thrombi at six hours $(\mathrm{p}=0.044)$.

\section{Effects of insonation angle on thrombus dissolution}

A total of 80 porcine arterial thrombi were utilized to compare the effects of transducer angulation. \% TD achieved using a 90 degree insonation angle with 2D ultrasound resulted in a significantly greater thrombus dissolution than with a 45 degree angle, irrespective of thrombus age (Table 3). This was observed for both three and six hour old thrombi. The effect of insonation angle was also seen with the $3 \mathrm{D}$ transducer, but this was not statistically significant $(\mathrm{p}<0.05)$.

\section{Inertial Cavitation Signals Within the Vessel}

PCD recordings from within the thrombus during representative treatments with and without microbubbles and presence or absence of the five and 10 centimeter thick TMP are demonstrated in Figure 7 for the two dimensional transducer. All data were obtained while the transducer was in high MI (1.1) mode. With the five centimeter TMP, there were still large spikes associated with collapsing bubbles (inertial cavitation) over the 100 second sampling period (left lower panel; Figure 6). Note that these large spikes were not seen when the high MI impulses were transmitted through the 10 centimeter thick TMP. Similar patterns and values were observed for cavitation monitoring from the 3D transducer (data not shown). Despite these differences, the \% TD was only slightly less at the 10 centimeter TMP thickness (Table 2).

\section{Discussion and Summary}

This study demonstrates that either a two or three dimensional diagnostic ultrasound transducer is capable of dissolving discrete thrombi in the presence of microbubbles, without the need for a fibrinolytic agent. The degree of effectiveness did depend on the age of the thrombus, and to some degree on the angle of the transducer beam with respect to the 
thrombus. However, the effectiveness of diagnostic ultrasound-induced thrombus dissolution in the presence of microbubbles was present even at tissue-mimicking depths of 10 centimeters, and did not appear to be dependent on the presence of inertial cavitation.

\section{Effect of Tissue Depth on Thrombus Dissolution}

Recent in vivo studies have shown that guided high MI impulses from a diagnostic ultrasound transducer (applied when microbubbles were visualized within the thrombosed vessels) can dissolve intravascular and microvascular thrombi (Xie et al. 2009a, 2009b). The presumptive mechanism for thrombus dissolution was cavitation of the microbubbles. Although there is some evidence that inertial cavitation occurs within the thrombus during these high MI applications (Xie et al. 2009a), it is unclear if inertial cavitation is required for the success of the technique. More recent in vitro studies have demonstrated that equivalent amounts of thrombus dissolution in the presence of fibrinolytic agents can be achieved at peak negative pressures that primarily generate stable cavitation (Datta et al. 2006). At the 10 centimeter TMP distance, the peak negative pressure from both the $2 \mathrm{D}$ and 3D transducer was less than half that seen at five centimeters, and there was a distinct loss of inertial cavitational spikes. Despite this, both the 2D and 3D transducers produced 47\% thrombus dissolution over the 10 minute insonation period through the 10 centimeter TMP, compared to 55-61\% dissolution at the five centimeter TMP thickness. This would indicate that inertial cavitation played a limited role in ultrasound and microbubble-mediated thrombus dissolution. Although we would presume stable cavitation still played a significant role, we did not examine for the signatures that would have confirmed this (i.e. sub and ultraharmonics). Nonetheless, these findings indicate that thrombus dissolution with ultrasound and microbubbles may be achievable even in settings where marked attenuation of the ultrasound beam occurs, such as with transcranial ultrasound in stroke and in acute coronary syndromes where the culprit vessel is located posteriorly.

\section{Effect of Thrombus Age}

Clinical studies have shown that the timing of fibrinolytic therapy is a key factor to the success of thrombotic recanalization. For example, optimal timing for fibrinolytic therapy in ischemic stroke has been shown to be within 3 hours of symptom onset (Adams HP et al 2007). On the other hand, the GISSI investigators obtained poor results for fibinolytic treatment initiated after 6 hours of symptom onset in acute myocardial infarction. (Gruppo Italiano per lo Studio della Streptochinasi nell'Infarto Miocardico (GISSI) 1986).

Thus, our goal was to examine how these different aged thrombi respond to ultrasound and microbubbles. As a thrombus matures, the platelets contract and pull fibrin fibers inward resulting in overall clot retraction and greater resistance to the mechanical disruptive forces of ultrasound and microbubble induced cavitation (Wohner 2008). In relatively fresh vascular thrombi in canines, we have observed microbubbles transiting through small channels within the thrombi during low MI ultrasound imaging even when angiographic occlusion is present (Xie et al. 2009a). In the present study, microbubbles transiting through these small channels were more frequently observed at three than six hours post thrombus formation. These channels serve as additional sites where cavitation induced by ultrasound can de-stabilize a thrombus. As the thrombus matures and these channels are closed by clot retraction, ultrasound and microbubble induced cavitation most likely only occurs at the thrombus surface, making it less effective at dissolving the thrombus. Although the degree of thrombus dissolution in our study was significantly less than that achieved with three hour old thrombi, it was still greater than what was seen with microbubbles alone. This would indicate that longer durations of ultrasound and microbubble exposure may be required to achieve thrombus dissolution of older thrombi. 


\section{Effect of Insonation Angle on Thrombus Dissolution}

Prior to this study, the effect of insonation angle on thrombus dissolution had not been examined. Such information becomes critical when using transthoracic ultrasound and microbubbles to dissolve coronary thrombi, where the beam insonation angle is often at angles with respect to the vessel thrombus or microvasculature. Because of the angle, the actual penetration of the ultrasound beam into the thrombus may vary significantly within different regions of the thrombus. Our results demonstrated that insonation angle with both the two and three dimensional transducers did affect the amount of thrombus dissolution. This finding suggested that attempts should be made to insonify perpendicular to the long axis of the thrombosed vessel when performing ultrasound mediated thrombolysis.

\section{Clinical implications}

Our findings indicate that diagnostic 2D or 3D ultrasound can dissolve thrombi with intravenous non-targeted MB even at tissue attenuation distances of up to 10 centimeters, but that this treatment modality is less effective for older thrombi. Ultrasound facilitated thrombolysis may have a significant impact on current therapies, and could alter the existing treatment regimens used in acute coronary syndromes. One additional factor not examined in this study was the effect of endogenous fibrinolytic activity. Further study in this vitro model could be performed using plasma as a perfusate instead of phosphate buffered saline to examine for this effect. One unique advantage of this therapy is that it is safe and minimally invasive (a peripheral intravenous line), and could therefore be delivered more rapidly than other therapies in acute coronary syndromes or stroke. Similar to current therapies, attention must be given to applying ultrasound and microbubbles as rapidly as possible after the onset of symptoms, since effectiveness wanes as the thrombus or embolus matures. Although the high MI impulses from the 2D and 3D ultrasound appeared equivalent in the degree of thrombus dissolution, 3D may have advantages in that it would cover a larger volume and thus more likely to consistently insonate the small thrombosed vascular targets such as coronary and intracerebral vessels.

Concerns have been raised as to potential harmful bioeffects that may occur with high MI impulses and microbubbles. Areas of cell death and hemorrhage have occurred within the myocardium with high MI impulses and microbubbles in relatively unattenuated settings (Ay et al 2001; Miller et al. 2006). Most of these unwanted effects are presumably due to inertial cavitation. Fortunately, our study would appear to indicate that peak negative pressures below the inertial cavitation threshold are sufficient to produce ultrasound and microbubble-mediated thrombus dissolution. Since there is a great degree of patient to patient variation in the degree of attenuation that occurs across the chest wall or temporal bone, it is evident that the optimal therapeutic transducer will require some form of feedback system to ensure one is below the inertial cavitation threshold, yet at an MI that is capable of producing thrombus dissolution.

\section{Acknowledgments}

The project described was supported in part by Award Number R01EB009050 from the National Institute of Biomedical Imaging And Bioengineering. We thank Gretchen Fry and Elizabeth Stolze for their technical assistance. The two and three-dimensional ultrasound system in this study was provided by Philips Healthcare.

\section{References}

Adams HP Jr, del Zoppo G, Alberts MJ, Bhatt DL, Brass L, Furlan A, Grubb RL, Higashida RT, Jauch EC, Kidwell C, Lyden PD, Morgenstern LB, Wureshi AI, Rosenwasser RH, Scott PA, Wijdicks EF. American Heart Association, American Stroke Association Stroke Council, Clinical Cardiology Council, Cardiovascular Radiology and Intervention Council, Atherosclerotic Peripheral Vascular 
Disease and Quality of Care Outcomes in Research Interdisciplinary Working Groups. Guidelines for the early management of adults with ischemic stroke: a guideline from the American Heart Association/American Stroke Council, Clinical Cardiology Council, Cardiovascular Radiology and Intervention Council, and the Atherosclerotic Peripheral Vascular Disease and Quality of Care Outcomes in Research Interdisciplinary Working Groups: the American Academy of Neurology affirms the value of this guideline as an education tool for neurologists. Stroke. 2007; 38:16551711. [PubMed: 17431204]

Ay T, Havaux X, Van Camp G, Campanelli B, Gisellu G, Pasquet A, Denef JF, Melin JA, Vanoverschelde JL. Destruction of contrast microbubbles by ultrasound: effects on myocardial function coronary perfusion pressure, and microvascular integrity. Circulation. 2001; 104:461-466. [PubMed: 11468210]

Datta S, Coussios C-C, McAdory LE, Tan J, Porter T, de Courten-Myers G, Holland CK. Correlation of cavitation with ultrasound enhancement of thrombolysis. Ultrasound Med Biol. 2006; 32:12571267. [PubMed: 16875959]

Dhond MR, Nguyen TT, Dolan C, Pulido G, Bommer WJ. Ultrasound-enhanced thrombolysis at 20 $\mathrm{KHz}$ with air-filled and perfluorocarbon-filled contrast biospheres. J Am Soc.Echocardiogr. 2000; 13:1025-1029. [PubMed: 11093105]

Gruppo Italiano per lo Studio della Streptochinasi nell'Infarto Miocardico (GISSI). Effectiveness of intravenous thrombolytic treatment in acute myocardial infarction. Lancet. 1986; 1:397-402. [PubMed: 2868337]

Hildick-Smith DJR, Shapiro LM. Coronary flow reserve improves after aortic valve replacement for aortic stenosis: an adenosine transthoracic echocardiography study. J Am Coll Cardiol. 2000; 36:1889-1896. [PubMed: 11092661]

Kawata H, Naya N, Takemoto Y, Uemura S, Nakajima T, Horii M, Takeda Y, Fujimoto S, Yamashita A, Asada Y, Saito Y. Ultrasound accelerates thrombolysis of acutely induced plateletrich thrombi similar to those in acute myocardial infarction. Circ J. 2007; 71:1643-1648. [PubMed: 17895565]

Miller DL, Driscoll EM, Dou C, Armstrong WF, Lucchesi BR. Microvascular permeabilization and cardiomyocyte injury provoked by myocardial contrast echocardiography in a canine model. $\mathrm{J}$ Am Coll Cardiol. 2006; 47:1464-1468. [PubMed: 16580537]

Molina CA, Ribo M, Rubiera M, Montaner J, Santamarina E, Delgado-Mederos R, Arenillas JF, Huertas R, Purroy F, Delgado P, Alvarez-Sabín J. Microbubble administration accelerates clot lysis during continuous 2-MHz ultrasound monitoring in stroke patients treated with intravenous tissue plasminogen activator. Stroke. 2006; 37:425-429. [PubMed: 16373632]

Ootaki Y, Kamohara K, Akiyama M, Zahr F, Kopcak MW Jr, Dessoffy R, Fukamachi K. Phasic coronary blood flow pattern during a continuous flow left ventricular assist support. Eur J Cardiothorac Surg. 2005; 28:711-716. [PubMed: 16198117]

Porter TR, LeVeen RF, Fox R, Kricsfeld A, Xie F. Thrombolytic enhancement with perfluorocoarbonexposed sonicated dextrose albumin microbubbles. Am Heart J. 1996; 132:964-968. [PubMed: 8892768]

Porter TR, Kricsfeld D, Lof J, Everbach EC, Xie F. Effectiveness of transcranial and transthoracic ultrasound and microbubbles in dissolving intravascular thrombi. J Ultrasound Med. 2001; 20:1313-1325. [PubMed: 11762543]

Siegel RJ, Atar S, Fishbein MC, Brasch AV, Peterson TM, Nagai T, Pal D, Nishioka T, Chae J, Birnbaum Y, Zanelli C, Luo H. Noninvasive transcutaneous low frequency ultrasound enhances thrombolysis in peripheral and coronary arteries. Echocardiography. 2001; 18:247-257. [PubMed: 11322908]

Suchkova VN, Baggs RB, Francis CW. Effect of $40 \mathrm{KHz}$ ultrasound on acute thrombotic ischemia in a rabbit femoral artery thrombosis model: enhancement of thrombolysis and improvement in capillary muscle perfusion. Circulation. 2000; 101:2296-2301. [PubMed: 10811598]

Tachibana K, Tachibana S. Albumin Microbubble Echo-contrast Material as an Enhancer for Ultrasound Accelerated Thrombolysis. Circulation. 1995; 92:1148-1150. [PubMed: 7648659]

Tiukinhoy-Laing SD, Huang S, Klegerman M, Holland CK, McPherson DD. Ultrasound-facilitated thrombolysis using tissue-plasminogen activator-loaded echogenic liposomes. Thromb Res. 2007; 119:777-784. [PubMed: 16887172] 
Wohner N. Role of cellular elements in thrombus formation and dissolution. Cardiovasc Hematol Agents in Med Chem. 2008; 6:224-228. [PubMed: 18673236]

Xie F, Tsutsui JM, Lof J, Unger EC, Johanning J, Culp WC, Matsunaga T, Porter TR. Effectiveness of Lipid Microbubbles and Ultrasound in Declotting Thrombosis. Ultrasound Med Biol. 2005; 31:979-985. [PubMed: 15972204]

Xie F, Everbach C, Matsunaga T, Lof J, He A, Bennett RM, Porter TR. Detection of Intravascular Cavitational Activity during Treatment of Deep Vessel Thromboses with Diagnostic Ultrasound and Intravenous Microbubbles. Circulation. 2007; 116:II_646.

Xie F, Lof J, Everbach C, He A, Bennett RM, Matsunaga T, Johanning J, Porter TR. Treatment of acute intravascular thrombi with diagnostic ultrasound and intravenous microbubbles. JACC Cardiovasc Imging. 2009; 2:511-518.

Xie F, Lof J, Matsunaga T, Zutshi R, Porter TR. Diagnostic Ultrasound Combined With Glycoprotein IIb/IIIa-Targeted Microbubbles Improves Microvascular Recovery After Acute Coronary Thrombotic Occlusions. Circulation. 2009; 119:1378-1385. [PubMed: 19255341] 


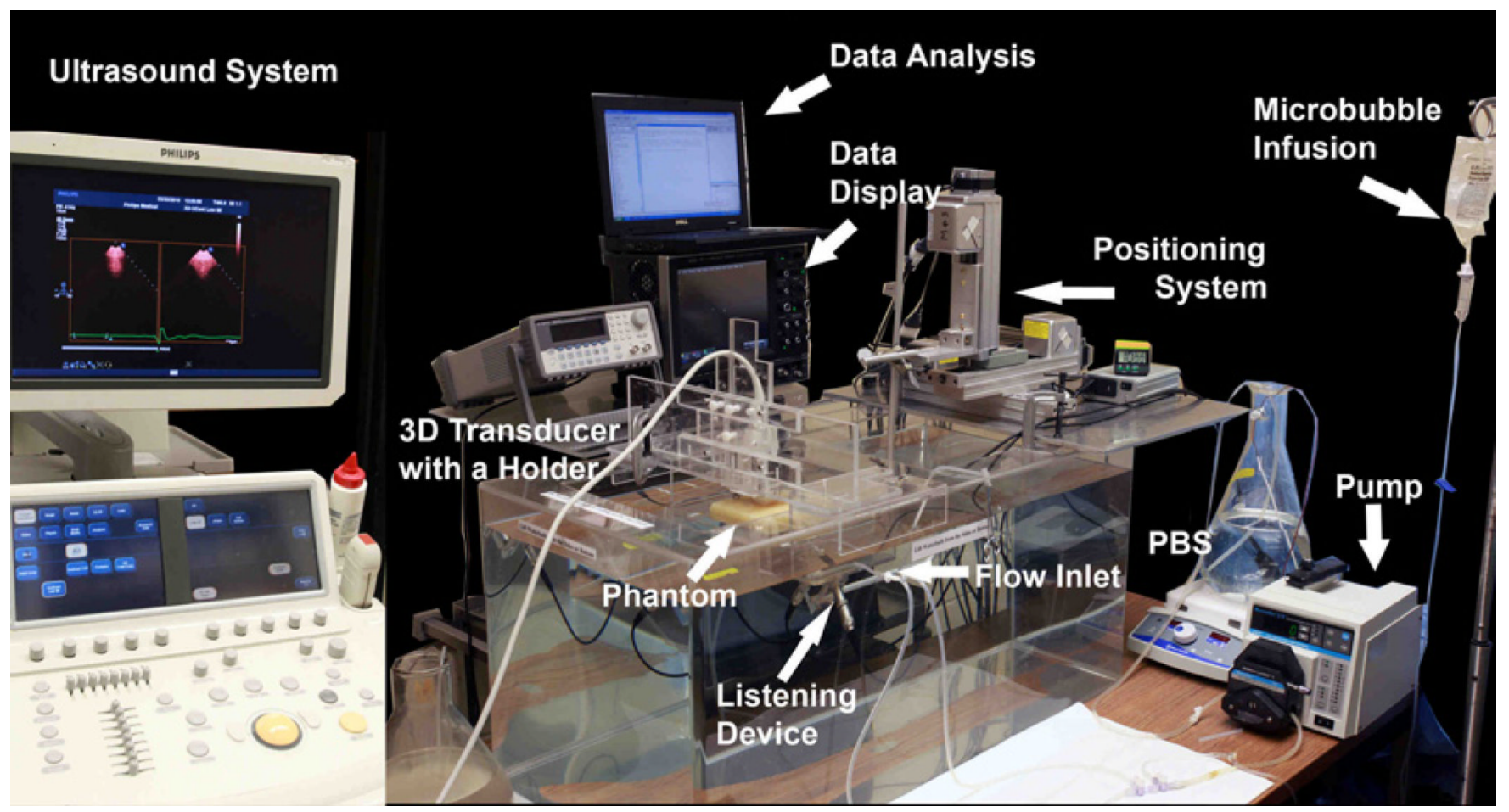

Figure 1.

Experimental set-up. The overall experimental arrangement consisted of an acrylic tank filled with distilled water. The set-up included a flow system, tissue-mimicking phantom with an adaptor module, cavitation detector/hydrophone positioning system, transducer positioning system, data display, collecting and analysis system, along with a two and threedimensional ultrasound system. See text for the details. 


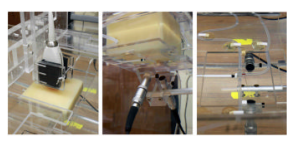

Figure 2.

A close-up of the occlusive thrombus placed beneath the phantom. 

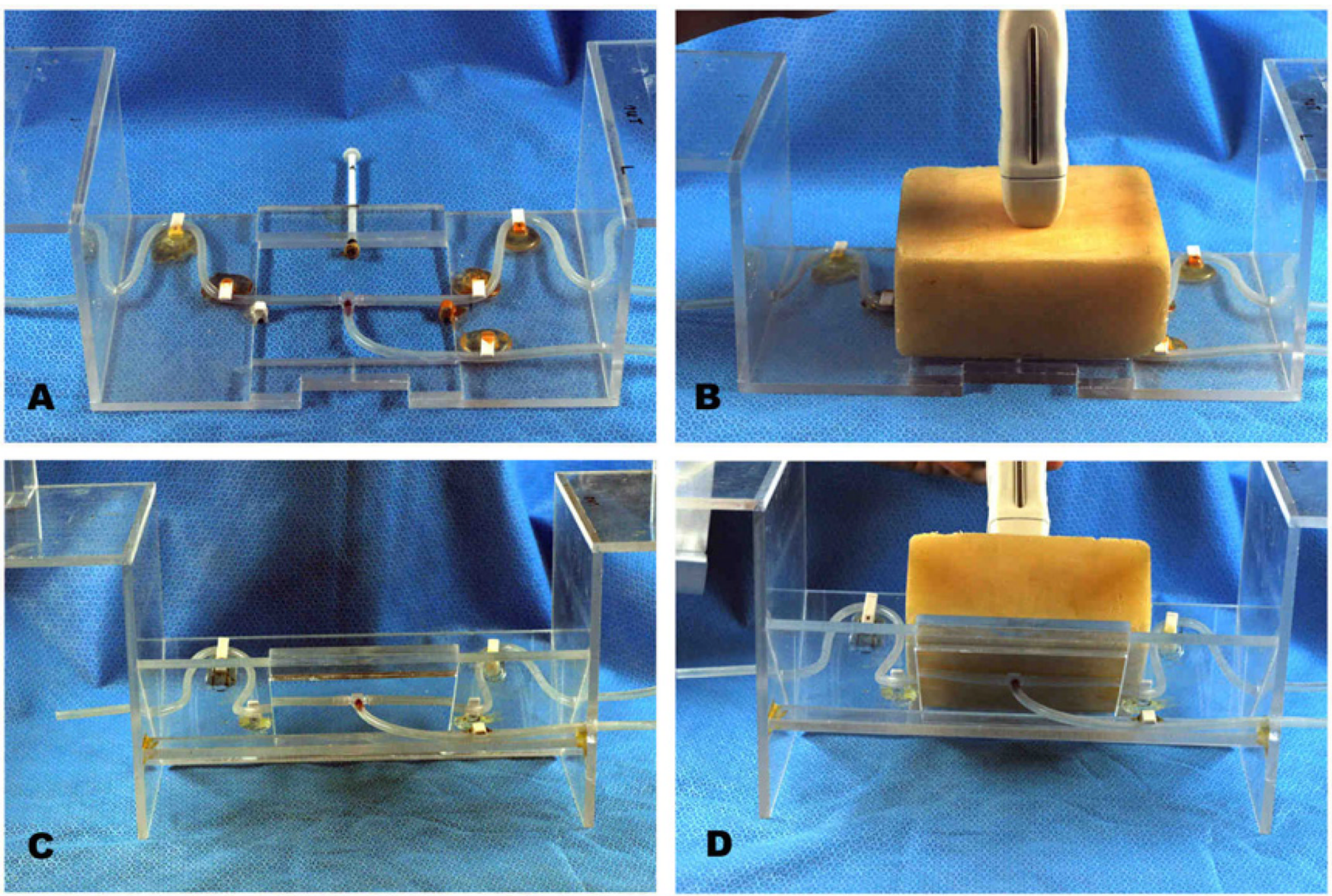

Figure 3.

Phantom adaptor modules with and without phantom. For the normal alignment study, the adaptor modules was placed as a flat level (Panel A and B). For the angulation study, a separate stand was used that permitted the phantom to sit at a 45 degree angle with respect to the thrombus (Panel C and D). The mark on the transducer shows the direction of long axis. See text for the details. 


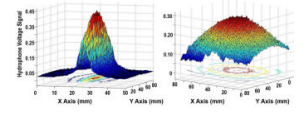

Figure 4.

The spatial distribution of peak negative pressure of three-dimensional ultrasound. The three-dimensional tranducer has a more uniform peak negative pressure distribution (right panel), while the two-dimensional transducer has a more central profile (left panel). 


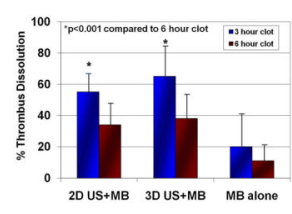

Figure 5.

Effect of thrombus age on $\%$ thrombus dissolution using $5 \mathrm{~cm}$ tissue mimicking phantom. 


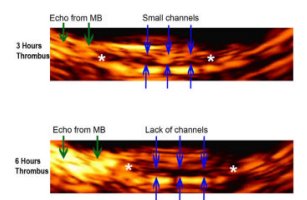

Figure 6.

An example of low MI imaging through an occlusive arterial thrombus at 3 hours versus 6 hours. Microbubbles are visualized transiting through small channels at 3 hours (upper panel), but not seen at 6 hours (lower panel). Reflections from microbubbles (MB) are seen proximal to the thrombus (green arrows). The blue arrows delineate the thrombus within the tubing. The asterisks indicate the length of the thrombotic occlusion. 


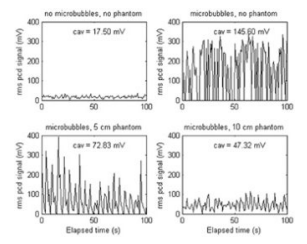

Figure 7.

Passive cavitation detection of inertial cavitation emissions during high-MI insonification of thrombus with 2D transducer. Integrated "cavitation dose" values shown are typical of both 2D and 3D transducers. Voltage measurements are root mean square values. 


\section{Table 1}

Peak negative pressure of two-dimensional and three-dimensional transducer with and without the tissue mimicking phantoms of varying thickness.

\begin{tabular}{lcccc}
\hline & \multicolumn{2}{c}{ 2D transducer } & \multicolumn{2}{c}{ 3D transducer } \\
\hline & $5 \mathrm{~cm}$ depth & $10 \mathrm{~cm}$ depth & $5 \mathrm{~cm}$ depth & $10 \mathrm{~cm}$ depth \\
In water & $0.848 \mathrm{MPa}$ & $0.762 \mathrm{MPa}$ & $0.779 \mathrm{MPa}$ & $0.452 \mathrm{MPa}$ \\
With phantom & $0.644 \mathrm{MPa}$ & $0.390 \mathrm{MPa}$ & $0.645 \mathrm{MPa}$ & $0.270 \mathrm{MPa}$ \\
\hline
\end{tabular}




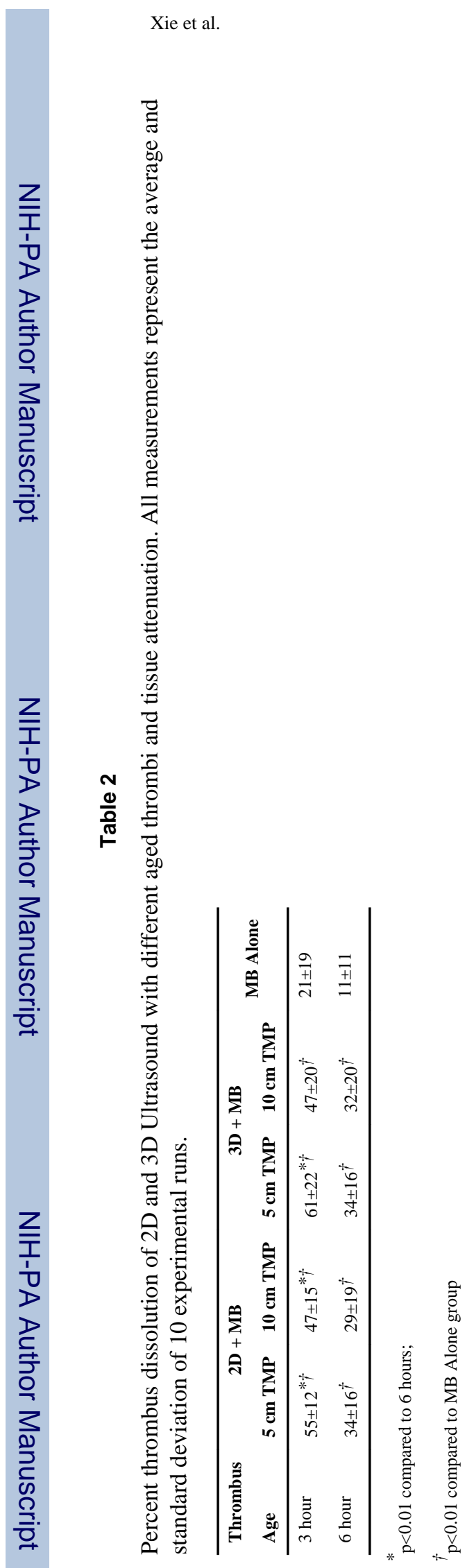

Ultrasound Med Biol. Author manuscript; available in PMC 2012 February 1. 
Table 3

Percent thrombus dissolution of DUS with different Angles of incidence

\begin{tabular}{lllll}
\hline & \multicolumn{2}{c}{ 2D Transducer } & \multicolumn{2}{c}{ 3D Transducer } \\
& $\mathbf{4 5}^{\circ}$ & $\mathbf{9 0}^{\circ}$ & $\mathbf{4 5}^{\circ}$ & $\mathbf{9 0}^{\circ}$ \\
\hline 3 hours & $41 \pm 20 \%$ & $51 \pm 14 \%^{*}$ & $48 \pm 17 \%$ & $54 \pm 22 \%$ \\
6 hours & $24 \pm 11 \%$ & $31 \pm 16 \%^{*}$ & $25 \pm 13 \%$ & $33 \pm 18$ \\
\hline$*$ & & & \\
p $<0.05$ compared to $45^{\circ}$ & & &
\end{tabular}

